\title{
Rotational isomerization of small carboxylic acids isolated in argon matrices: Tunnelling and quantum yields for the photoinduced processes
}

\author{
Ermelinda M. S. Maçôas, ${ }^{a b}$ Leonid Khriachtchev, ${ }^{* a}$ Mika Pettersson, $\dagger^{a}$ Rui Fausto ${ }^{b}$ and \\ Markku Räsänen ${ }^{a}$ \\ ${ }^{a}$ Laboratory of Physical Chemistry, University of Helsinki, PO Box 55, FIN-00014 Helsinki, \\ Finland. E-mail: leonid.khriachtchev@helsinki.fi \\ ${ }^{\boldsymbol{b}}$ Department of Chemistry (CQC), University of Coimbra, P-3004-535 Coimbra, Portugal
}

Received 1st November 2004, Accepted 17th December 2004

First published as an Advance Article on the web 12th January 2005

\begin{abstract}
The quantum yields for internal rotation around the $\mathrm{C}-\mathrm{O}$ bond induced by excitation of the first overtone of the hydroxyl stretching mode in formic, acetic, and propionic acids isolated in solid Ar are comparatively discussed. The tunnelling kinetics for isomerization from the higher energy arrangement of the carboxylic group (cis) to the lower energy arrangement (trans) in this series of compounds is also analysed. Finally, the quantum yield for the $\mathrm{C}_{\alpha}-\mathrm{C}$ isomerization in propionic acid was investigated and, in contrast with the $\mathrm{C}-\mathrm{O}$ isomerization, shown to be probably sensitive to the local matrix morphology.
\end{abstract}

\section{Introduction}

For a number of molecules, rotational isomerization can be efficiently induced by vibrational excitation of the monomer isolated in low-temperature rare-gas matrices. ${ }^{1-19}$ This process occurs when the energy deposited into the initially excited vibrational mode is transferred to the reaction coordinate. The mechanism of energy relaxation in the solid was described as a phonon-assisted intramolecular vibrational energy relaxation (IVR) where the lattice modes provide a thermal bath compensating the energy mismatch between the intramolecular vibrational states. ${ }^{20,21}$ The relaxation rates are expected to depend on both the number of phonons involved and temperature of the phonon bath.

The experimental quantum yields for IR-induced rotamerization (rotational isomerization) in rare-gas matrices have been previously reported. ${ }^{1,11-13}$ The quantum isomerization yield depends on the proportion of the energy relaxation channels that can deposit energy into the reaction coordinate as well as on the lifetimes of the molecular states involved so that the isomerization is in competition with possible nonreactive energy relaxation channels. The excitation energy, the host, and the nature of the excited mode may affect the IVR process and, consequently, they have been shown to affect the isomerization quantum yields. ${ }^{11}$

For formic ( $\mathrm{HCOOH}, \mathrm{FA})$ and acetic $\left(\mathrm{CH}_{3} \mathrm{COOH}, \mathrm{AA}\right)$ acids, two stable geometrical arrangements are interconverted by rotation around the $\mathrm{C}-\mathrm{O}$ axis, the trans and cis conformers shown in Fig. 1 (C-C-O-H dihedral angles of 180 and $0^{\circ}$, respectively). ${ }^{5,22}$ The trans form is lower in energy by $\approx 1400$ $1800 \mathrm{~cm}^{-1}$ and the trans $\rightarrow$ cis isomerization barrier is $\approx 3900$ $4400 \mathrm{~cm}^{-1} \cdot{ }^{23-26}$ These molecules were found mainly in the trans conformation in low-temperature matrices. ${ }^{5,22}$ The resonant narrowband irradiation of individual vibrational transitions of the matrix isolated molecules in the $2900-7000 \mathrm{~cm}^{-1}$ region induces the trans $\rightarrow$ cis conversion. ${ }^{26-28}$ Infrared (IR) absorption spectroscopy provides reliable identification of the

$\dagger$ Present address: Department of Chemistry, University of Jyväskylä, PO Box 35, FIN-40014, Finland. conformers because certain modes are very sensitive to conformation (see Table 1). For both FA and AA, the reverse isomerization from the higher energy conformer ( $c i s)$ to the conformational ground state (trans) takes place by tunnelling. ${ }^{28,29}$

Intuitively, isomerization may take place when the energy transferred to the reaction coordinate $(\mathrm{C}-\mathrm{O}$ torsion, $\tau \mathrm{C}-\mathrm{O})$ is higher than the isomerization barrier. However, for FA and AA, it was shown that this reaction occurs even when the excitation energy deposited into the reaction coordinate is below the isomerization barrier, ${ }^{26-28}$ suggesting that tunnelling plays an important role in the photoinduced trans $\rightarrow$ cis isomerization process.

The effects of the medium and the nature of the excited state in the trans $\rightarrow$ cis isomerization have also been studied. ${ }^{26,28}$ For FA, the quantum yield is practically independent of the local environment (matrix site), except when associated with excitation of hindered rotation of the molecule in the matrix. ${ }^{26}$ Since AA shows no site structure, the matrix site effect on the quantum yield was not addressed. However, for AA, the isomerization quantum yield upon excitation of the $2 \nu \mathrm{OH}$ mode was shown to be relatively insensitive to the host (Ar, $\mathrm{Kr}$, and $\mathrm{Xe}$ ). ${ }^{28}$ Additionally, excitation of different modes at energies higher than the barrier leads to similar isomerization quantum yields independently of the excited mode $(\approx 20 \%$ for FA, and $\approx 2 \%$ for AA). ${ }^{26,28}$ Therefore, the nature of the excited mode does not seem to be an important factor to the photoisomerization efficiency in these molecules.

The high efficiency of the isomerization process in FA was connected with the relatively large energy gaps in the vibrational manifold of this molecule, which delays the energy relaxation within the potential well of the initially excited conformer, hence favoring isomerization. ${ }^{26}$ It was suggested that the one order of magnitude difference between the quantum yields for FA and AA is due to the methyl group in AA, which increases the number of energy relaxation channels competing with the photoisomerization process. ${ }^{28}$ The important role of the methyl group in the photoisomerization process was supported by a large increase of the trans $\rightarrow$ cis isomerization quantum yield upon deuteration of the methyl group 


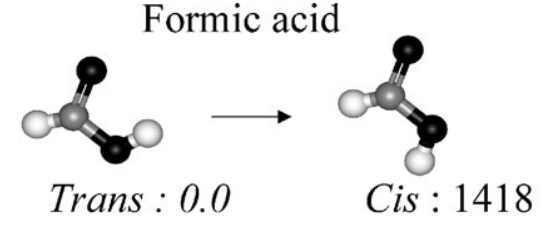

Acetic acid

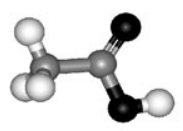

Trans : 0.0

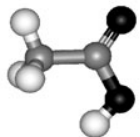

Cis: 1831
Propionic acid
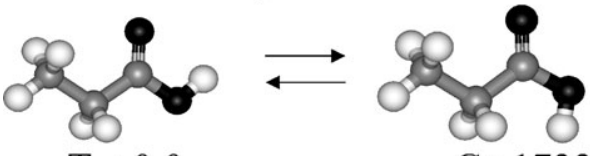

$\mathrm{T}_{\mathrm{t}}: 0.0$ $\mathrm{C}_{\mathrm{t}}: 1733$
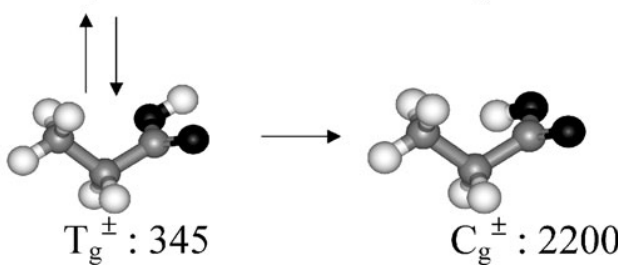

Fig. 1 Conformers of FA, AA and PA. The conformational energies calculated at the MP2/6-311++G(2d,2p) level of theory (in $\left.\mathrm{cm}^{-1}\right)$ are shown. The arrows indicate the observed IR-induced isomerization processes. The IR-induced cis $\rightarrow$ trans process for FA has not been studied. The computational trans $\rightarrow$ cis barriers are 4096 and 4139 $\mathrm{cm}^{-1}$ for FA and AA, respectively. For PA, the $T_{t} \rightarrow C_{t}, T_{\mathrm{g}}^{ \pm} \rightarrow C_{\mathrm{g}}{ }^{ \pm}$, $T_{t} \rightarrow T_{\mathrm{g}}^{ \pm}$and $C_{t}, \rightarrow C_{\mathrm{g}}^{ \pm}$barriers are $4023,4091,405$ and $559 \mathrm{~cm}^{-1}$, respectively. The barriers are given taking into account the zero point energies.

(by a factor of $\approx 5$ ). ${ }^{28}$ For AA, deuteration of the hydroxyl group was shown to reduce the isomerization quantum yield, in contrast to the effect observed for deuteration of the methyl group. In $\mathrm{CH}_{3} \mathrm{COOD}$ (AA-OD), the trans $\rightarrow$ cis quantum yield is almost one order of magnitude lower than in the fully hydrogenated species (AA-OH). ${ }^{28}$ Additionally, for $\mathrm{CH}_{3} \mathrm{COOD}$ and $\mathrm{CD}_{3} \mathrm{COOD}$, the trans $\rightarrow$ cis isomerization process has a lower quantum yield than the reverse IR-induced cis $\rightarrow$ trans process. ${ }^{28}$ Similar observations have been reported for HONO isolated in solid $\mathrm{Kr}^{1}$

Propionic acid $\left(\mathrm{CH}_{3} \mathrm{CH}_{2} \mathrm{COOH}, \mathrm{PA}\right)$ has one additional internal rotational degree of freedom when compared with $\mathrm{AA}$, the internal rotation around the $\mathrm{C}_{\alpha}-\mathrm{C}$ bond. With respect to the $\mathrm{C}-\mathrm{O}$ rotation, $\mathrm{PA}$ is similar to $\mathrm{FA}$ and $\mathrm{AA}$. Recently, the four PA conformers built up from combinations of the stable $\mathrm{C}-\mathrm{O}$ (trans and cis) and $\mathrm{C}_{\alpha}-\mathrm{C}$ (trans and gauche, with $\mathrm{C}-\mathrm{C}-\mathrm{C}-\mathrm{O}$ dihedral angles of $180^{\circ}$ and $\pm \approx 75^{\circ}$, respectively) arrangements have been identified using IR-induced isomerization in solid
Ar. ${ }^{30}$ The structure and energetics of the PA conformers predicted by $a b$ initio calculations are shown in Fig. 1 and the characteristic vibrational frequencies for the $T_{t}$ and $C_{t}$ forms are given in Table 1. The IR-induced isomerization processes identified for PA isolated in solid Ar are also indicated in Fig. 1. The quantification of the isomerization quantum yields for the $\mathrm{C}-\mathrm{O}$ and $\mathrm{C}_{\alpha}-\mathrm{C}$ rotations in propionic acid gives further insight into factors affecting the rotamerization process.

In the present work, we compare IR-induced rotational isomerization and tunnelling processes for formic, acetic and propionic acids in solid Ar. The data for FA and AA were previously reported, ${ }^{26,28}$ and the results for PA are described here for the first time. By analysing comparatively the data obtained for all these species, it is possible to test previous interpretations and understand better how the vibrational density of states, deuteration of the hydroxyl group, and the matrix surrounding affect the isomerization process. It is not a purpose of this article to describe in detail spectroscopic identification and properties of the four PA conformers, and we present here only limited spectroscopic data (see Table 1).

\section{Experimental details and methodology}

The gaseous samples were prepared by mixing the carboxylic acids ( $>99 \%$ ), degassed by several freeze-pump-thaw cycles, with high purity argon $(99.9999 \%)$, in the $1: 500$ to $1: 2000$ ratio. Hydroxyl-deuterated PA was obtained by $\mathrm{H} / \mathrm{D}$ exchange on the inner surface of the sample container and the deposition line saturated with $\mathrm{D}_{2} \mathrm{O}$. The gaseous mixtures were deposited onto a CsI substrate kept at $15 \mathrm{~K}$ in a closed cycle helium cryostat (APD, DE 202A) and subsequently cooled down to 8 $\mathrm{K}$. The IR absorption spectra $\left(7900-400 \mathrm{~cm}^{-1}\right)$ were measured with a Nicolet SX-60 FTIR spectrometer. A liquid-nitrogen cooled MCT detector and a $\mathrm{Ge} / \mathrm{KBr}$ beamsplitter were used to record the mid-IR absorption spectra with spectral resolution from 0.25 to $1.0 \mathrm{~cm}^{-1}$. A liquid-nitrogen-cooled InSb detector and a quartz beamsplitter were used to record the near-IR (NIR) absorption spectra with spectral resolution of $0.5 \mathrm{~cm}^{-1}$. Typically 100 to 500 interferograms were co-added.

Tunable pulsed IR radiation provided by an optical parametric oscillator (Continuum, OPO Sunlite with IR extension) was used to excite vibrations of the studied molecules. The pulse duration was $\approx 5 \mathrm{~ns}$, the spectral linewidth $\approx 0.1 \mathrm{~cm}^{-1}$ and the repetition rate $10 \mathrm{~Hz}$. The pulse energy of the OPO in the $7000-5000 \mathrm{~cm}^{-1}$ spectral region was $\approx 0.5 \mathrm{~mJ}$. The OPO radiation frequency was measured with a Burleigh WA-4500 wavemeter providing an absolute accuracy better than $1 \mathrm{~cm}^{-1}$ for the IR pumping radiation. The pumping beam was quasicollinear with the spectrometer beam, and interference filters (transmitting in the $3650-3400 \mathrm{~cm}^{-1}$ or $3300-1100 \mathrm{~cm}^{-1}$ regions) were placed in front of the detector to prevent its exposure to the pumping radiation while recording spectra during irradiation.

Table 1 Experimental characteristic frequencies for the conformers of FA, AA and PA exhibiting the trans or cis arrangements of the carboxylic group $\left(\mathrm{C}-\mathrm{C}-\mathrm{O}-\mathrm{H} \text { dihedral angle of } 180^{\circ} \text { and } 0^{\circ} \text {, respectively }\right)^{30,32,33}$

\begin{tabular}{|c|c|c|c|c|c|c|}
\hline & \multicolumn{2}{|l|}{ trans } & \multicolumn{4}{|l|}{ cis } \\
\hline & $\nu \mathrm{OH}(\mathrm{D})$ & $\nu \mathrm{C}=\mathrm{O}$ & $\nu \mathrm{OH}(\mathrm{D})$ & $\nu \mathrm{C}=\mathrm{O}$ & {$[\Delta \nu \mathrm{OH}(\mathrm{D})]_{\text {cis-trans }}$} & {$[\Delta \nu \mathrm{C}=\mathrm{O}]_{\text {cis-trans }}$} \\
\hline $\mathrm{HCOOH}$ & 3550 & 1768 & 3617 & 1808 & +67 & +40 \\
\hline $\mathrm{DCOOH}$ & 3550 & 1761 & 3616 & 1777 & +66 & +16 \\
\hline $\mathrm{CH}_{3} \mathrm{COOH}$ & 3564 & 1779 & 3623 & 1807 & +59 & +28 \\
\hline $\mathrm{CD}_{3} \mathrm{COOH}$ & 3564 & 1777 & - & 1798 & - & +21 \\
\hline $\mathrm{CH}_{3} \mathrm{COOD}$ & 2629 & 1770 & 2674 & 1800 & +45 & +30 \\
\hline $\mathrm{CD}_{3} \mathrm{COOD}$ & 2630 & 1765 & 2673 & 1794 & +43 & +29 \\
\hline $\mathrm{CH}_{3} \mathrm{CH}_{2} \mathrm{COOH}$ & 3567 & 1776 & - & 1802 & - & +26 \\
\hline $\mathrm{CH}_{3} \mathrm{CH}_{2} \mathrm{COOD}$ & 2630 & 1766 & 2674 & 1797 & +44 & +31 \\
\hline
\end{tabular}


The $a b$ initio calculations were performed using the GAUSSIAN98 program at the MP2/6-311++G(2d,2p) level of approximation. $^{31}$

The quantum yields of the rotamerization processes, $\phi(i)$, were extracted from the following equation:

$$
\phi(i)=\frac{k_{\mathrm{p}}(\nu)}{\sigma^{i}(\nu) I(\nu)}
$$

where $k_{\mathrm{p}}(\nu)$ (in $\mathrm{s}^{-1}$ ) is the averaged isomerization rate upon pumping at the frequency $\nu, \sigma^{i}(\nu)$ (in $\mathrm{cm}^{2}$ ) is the absorption cross-section of the mode $i$ at the excitation frequency, and $I$ (in $\mathrm{s}^{-1} \mathrm{~cm}^{-2}$ ) is the averaged photon intensity of the pumping beam. The cross-section is obtained using the measured IR absorption at the excitation frequency, the estimated concentration of molecules in the excited matrix site, and the matrix thickness. For PA, the absorption cross-sections at the frequency used to excite the $2 \nu \mathrm{OH}$ and $2 \nu \mathrm{OD}$ modes of $T_{t}$ are $\approx 3.6 \times 10^{-20} \mathrm{~cm}^{2}$, and $(3.2-4.1) \times 10^{-20} \mathrm{~cm}^{2}$ (depending on the matrix site), respectively. For the $2 \nu \mathrm{OH}$ mode, the crosssections for PA is smaller than the value obtained for the same mode of FA and AA by a factor of $\approx 5$. In the case of the $2 \nu \mathrm{OD}$ mode, the $\sigma$ values are $\approx 2-3$ times smaller for PA than for AA (the value for FA has not been reported). These values correspond to the maximum of the absorption bands, and the smaller values for PA reflect essentially the fact that these bands are broader for PA than for FA and AA. The absorption cross-section of the $2 \nu \mathrm{OD}$ mode of the $C_{t}$ conformer could not be measured directly due to its low concentration in the matrix. It was assumed that the absorption cross-section of the $2 \nu \mathrm{OD}$ mode of $C_{t}$ is similar to the value for $T_{t}$ by analogy with the data for cis and trans AA-OD.

Two methodologies have been applied to determine the pumping rate, $k_{\mathrm{p}}$ in eqn. (1). The most straightforward approach employs the IR-induced formation kinetics of the conformers. This approach was previously applied to the estimation of isomerization quantum yields for AA-OD. ${ }^{28}$ In the present work, the PA concentration was followed by measuring the integrated absorption of the $\nu \mathrm{OH}$ or $\nu \mathrm{OD}$ modes upon IR pumping. To minimize errors on the determination of the pumping rates caused by reverse isomerization processes, only the points obtained during the first minutes of irradiation were considered. As an example, Fig. 2 shows the IR-induced formation kinetics for two conformers of AA-OD (trans and cis) and PA-OD $\left(T_{t}\right.$ and $\left.C_{t}\right)$.

The kinetics-based methodology could be used when the reverse isomerization was relatively slow. This is not the case for the $T_{t} \rightarrow C_{t}$ process in $\mathrm{PA}-\mathrm{OH}$ where the backreaction taking place by tunnelling is too fast to follow reliably the pumping kinetics. The $C_{t}$ concentration saturates very quickly at a quite low level upon pumping the $2 \nu \mathrm{OH}$ mode of the $T_{t}$ form. This stationary state is established as a result of the interplay between photoinduced generation of the $C_{t}$ conformer and its depletion due to the $C_{t} \rightarrow T_{t}$ tunnelling. In this case, a way to obtain the pumping rate follows the procedure previously reported for the hydrogenated isotopologues of FA and $\mathrm{AA} \cdot{ }^{26,28}$ At the equilibrium the pumping and tunnelling rates are equal, then:

$$
k_{\mathrm{p}}(\nu)\left[T_{t}\right]_{\mathrm{eq}}=k_{t}(T)\left[C_{t}\right]_{\mathrm{eq}}
$$

where $k_{t}(T)$ is the tunnelling rate coefficient at the temperature $T$. Hence, the pumping rate can be determined from the measured $C_{t} \rightarrow T_{t}$ tunnelling rate and the ratio of the $T_{t}$ and $C_{t}$ equilibrium concentrations. The tunnelling rate is extracted from the decay kinetics of the $C_{t}$ conformer (see Fig. 3), which is obtained by recording IR absorption spectra every $10 \mathrm{~s} \mathrm{co-}$ adding only 5 interferograms for each spectrum. The $C_{t} / T_{t}$ concentration ratio at the equilibrium can be extracted from the changes in integrated absorptions upon pumping as described previously for FA. ${ }^{26}$ The most important error of the

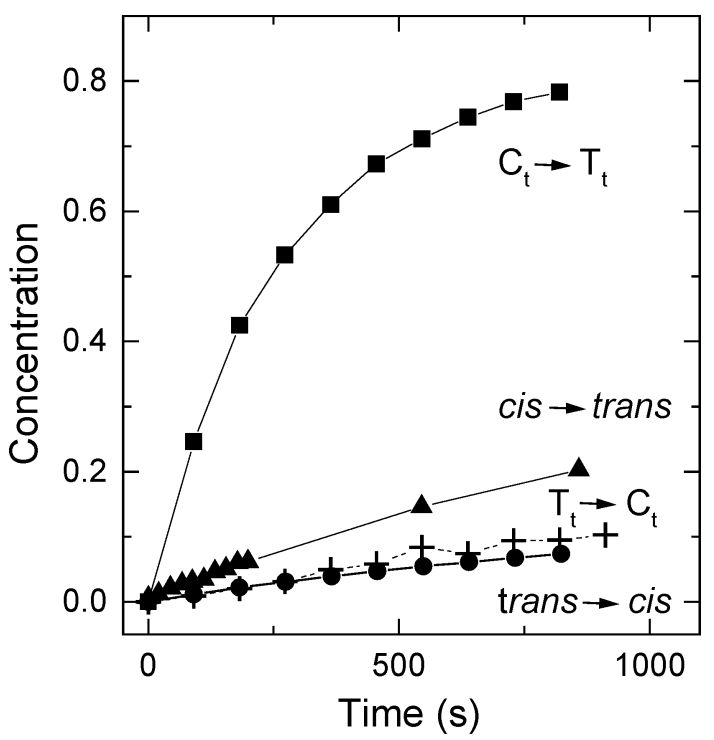

Fig. 2 Pumping kinetics measured for hydroxyl-deuterated AA and PA. The concentrations of the photoproducts are normalised by the initial concentrations of the pumped conformer. The pumping rates are extracted from a linear fit of the beginning of the kinetics curves. For AA, the pumping rates for the trans $\rightarrow$ cis $(\mathbf{O})$ and cis $\rightarrow$ trans $(\boldsymbol{\Delta})$ processes differ by a factor of $\approx 3$, whereas for PA, the rates for the $T_{t} \rightarrow C_{t}(+)$ and $C_{t} \rightarrow T_{t}(\boldsymbol{\square})$ processes differ by a factor of $\approx 25$. The lines are merely guides. The $T_{t}$ and $C_{t}$ conformers in the LF site were pumped.

isomerization quantum yield obtained from eqn. (1) can come from the estimated proportion of molecules isolated in various matrix sites, independently of the method used to obtain $k_{\mathrm{p}}$. It was assumed here that the absorption intensity is independent of the matrix site.

As another approach, the quantum yield is a ratio of the number of molecules that undergo isomerization $\left(N_{\text {iso }}\right)$ to the number of absorbed photons $\left(N_{\mathrm{abs}}\right)$ :

$$
\phi(i)=\frac{N_{\text {iso }}}{N_{\text {abs }}}
$$

The value of $N_{\text {abs }}$ per unit time is estimated from the absorbance at the excitation frequency, $A_{\text {exc }}$, the intensity of the

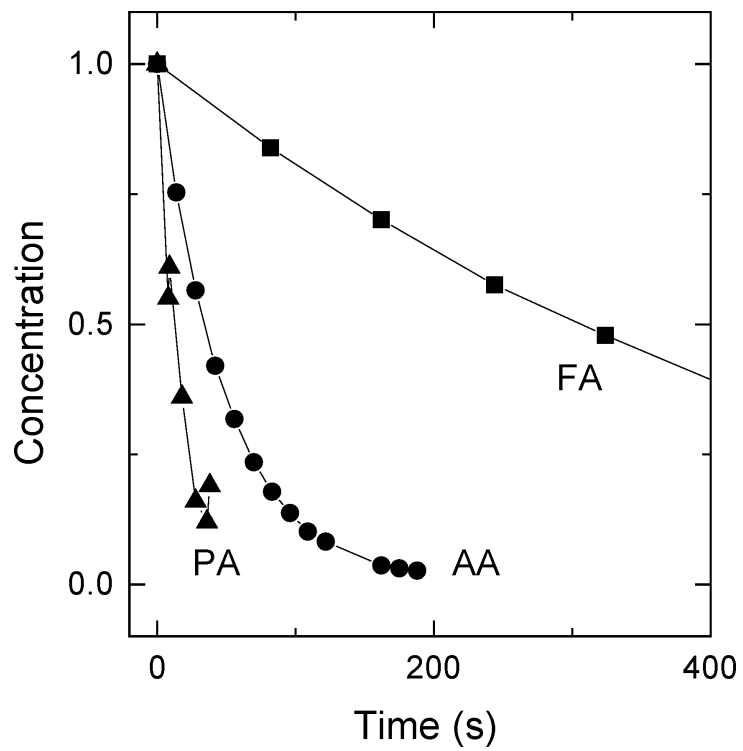

Fig. 3 Tunnelling kinetics for the conversion from the higher energy ( cis) to the lower energy (trans) arrangement of the carboxylic group of fully hydrogenated FA $(\boldsymbol{\square}$, cis $\rightarrow$ trans $)$, AA $(\bullet, c i s \rightarrow$ trans $)$ and PA $\left(\boldsymbol{\Lambda}, C_{t} \rightarrow T_{t}\right)$ measured in solid Ar at $8 \mathrm{~K}$. The lines are merely guides. The data are normalised by the initial concentrations. 
incoming beam (in $\mathrm{cm}^{-2} \mathrm{~s}^{-1}$ ), $I_{0}$, and the irradiated area, $S$, as follows:

$$
N_{\mathrm{abs}}=\left(1-10^{-\mathrm{A}_{\mathrm{exc}}}\right) I_{0} S
$$

The number of isomerization events per unit time is calculated as follows:

$$
N_{\text {iso }}=\frac{\left(\frac{\Delta A}{A_{0}}\right) n}{\Delta t}
$$

where $\Delta t$ is the irradiation time, $n$ is the total number of molecules of the excited conformer, $A_{0}$ and $\Delta A$ are the initial integrated absorption and the change in integrated absorption for a given vibrational mode of the pumped conformer. $\Delta A$ is related to isomerization induced in a specific site, and it is measured directly from the difference IR absorption spectra. Note that $\Delta A$ for a given pumping time can be estimated only if the pumping kinetics is followed in real time, and $N_{\text {abs }}$ can only be estimated if the NIR spectrum is measured before pumping.

\section{Results and discussion}

\subsection{Identification of the conformers by IR absorption spectroscopy}

For various isotopologues of FA and AA, excitation of the $2 \nu \mathrm{OH}(\mathrm{D})$ modes is efficient in promoting isomerization around the $\mathrm{C}-\mathrm{O}$ bond $\left(\mathrm{C}-\mathrm{O}\right.$ isomerization). ${ }^{26,28}$ The IRinduced changes in the $\nu \mathrm{OH}(\mathrm{D})$ and $\nu \mathrm{C}=\mathrm{O}$ spectral region can be used to identify the conformers involved because they are very sensitive to the conformation of the carboxylic group (see Table 1). For FA and AA, the $\nu \mathrm{OH}(\mathrm{D})$ and $\nu \mathrm{C}=\mathrm{O}$ modes appear blue-shifted by $40-60$, and $20-40 \mathrm{~cm}^{-1}$, respectively, in the cis as compared with the trans conformer. ${ }^{32,33}$ For FA and AA, the traces (a) and (b) in Fig. 4 show the difference IR spectra where the increasing bands of the cis forms are clearly blue-shifted from the decreasing bands of the trans forms.

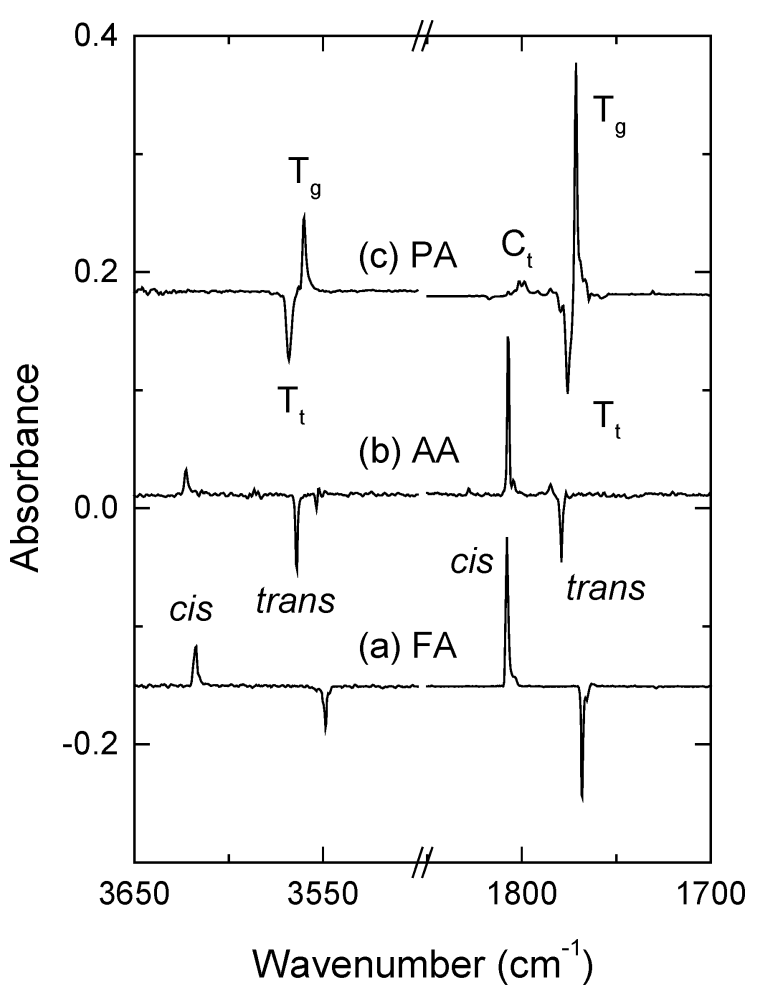

Fig. 4 Difference IR absorption spectra showing the spectral changes produced by excitation at the $2 \nu \mathrm{OH}$ frequencies of the ground state conformers of fully hydrogenated FA (a), AA (b) and PA (c). The difference spectra are obtained as spectra measured after pumping minus spectra measured before pumping for FA and AA, and a spectrum during pumping minus a spectrum before pumping for PA.
Similarly to FA and AA, PA is found after deposition in the ground conformational state, the $T_{t}$ form (see Table 1 for the characteristic vibrational frequencies). ${ }^{30}$ Excitation of the $2 \nu \mathrm{OH}(\mathrm{D})$ mode of $T_{t}$ induces the $\mathrm{C}-\mathrm{O}$ and $\mathrm{C}_{\alpha}-\mathrm{C}$ isomerizations, which lead to the production of the $C_{t}$ and $T_{\mathrm{g}}{ }^{ \pm}$conformers, respectively. The bands of $C_{t}$ are most clearly observed in the spectra recorded under pumping of $T_{t}$ because its concentration quickly decreases when the excitation of $T_{t}$ is interrupted, even at $8 \mathrm{~K}$ (see Fig. 3). The $C_{t}$ form converts back to the most stable $T_{t}$ form by tunnelling, in analogy with the cis $\rightarrow$ trans tunnelling observed for FA and AA. ${ }^{28,29}$ For PA, trace (c) in Fig. 4 shows a difference spectrum obtained under excitation of the $2 \nu \mathrm{OH}$ mode of $T_{t}$. In this spectrum the emerging bands slightly red-shifted from those of $T_{t}$, in both the $\nu \mathrm{OH}$ and $\nu \mathrm{C}=\mathrm{O}$ spectral regions are assigned to the $T_{\mathrm{g}}{ }^{ \pm}$ form resulted from the $\mathrm{C}_{\alpha}-\mathrm{C}$ internal rotation. These small shifts agree with a predictable small effect of the backbone conformation on the vibrational modes localized in the carboxylic group. The weaker band rising at $\approx 1800 \mathrm{~cm}^{-1}$ is assigned to the $\nu \mathrm{C}=\mathrm{O}$ mode of $C_{t}$, which is produced from $T_{t}$ by internal rotation along the $\mathrm{C}-\mathrm{O}$ bond. The $\nu \mathrm{C}=\mathrm{O}$ band of $C_{t}$ shows the expected large blue-shift from that of $T_{t}$. The $\nu \mathrm{OH}$ band is not observed for $C_{t}$ most probably due to its low intensity and also due to the fact that it is expected to appear at $\approx 3630 \mathrm{~cm}^{-1}$, which is very close to the cut-off of the filter used to record the spectrum under irradiation.

As an important fingerprint of tunnelling, substitution of the tunnelling particle by a heavier isotope decreases the reaction rate significantly. Consequently, deuteration of the hydroxyl group of PA facilitates identification of the $C_{t}$ conformer produced upon excitation of the ground-state $T_{t}$ form. Spectra (a) and (b) in Fig. 5 show the results of conformational isomerization of PA-OD induced by excitation of the $T_{t}$ form in two different matrix sites at 5175 and $5170 \mathrm{~cm}^{-1}$ (hereafter denoted as HF and LF, respectively). Similarly to PA-OH, the

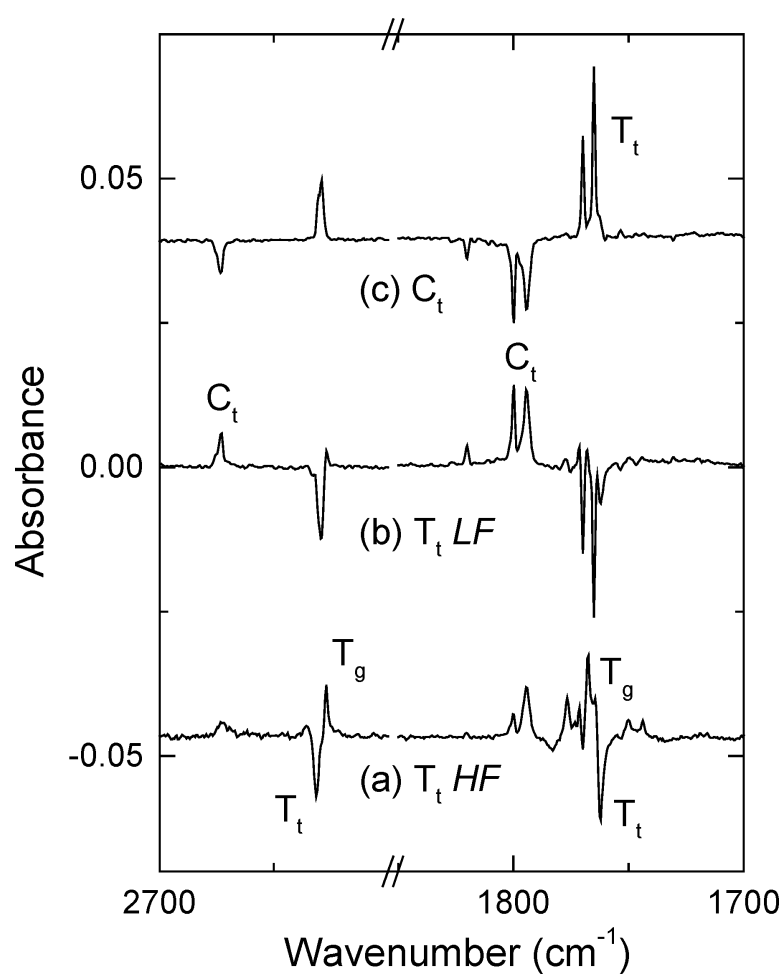

Fig. 5 Difference IR absorption spectra of PA-OD showing the conformational changes induced by excitation of the $2 \nu \mathrm{OD}$ modes of (a) $T_{t}$ in the HF site (40 min), (b) $T_{t}$ in the LF site (40 min), and (c) $C_{t}$ in the LF matrix site (15 min). Traces (a) and (b) show the increasing of $C_{t}$ and $T_{\mathrm{g}}{ }^{ \pm}$bands produced from $T_{t}$ via the $\mathrm{C}-\mathrm{O}$ and $\mathrm{C}_{\alpha}-\mathrm{C}$ isomerization and trace (c) shows the increasing of $T_{t}$ bands produced from $C_{t}$ due to the $\mathrm{C}-\mathrm{O}$ isomerization. The pumped species are marked. 
increasing bands in the two difference spectra, which appear considerably blue-shifted from the $T_{t}$ bands, are assigned to the $C_{t}$ conformer while the less shifted bands are due to the $T_{\mathrm{g}}{ }^{ \pm}$ conformer. In agreement with our calculations, the $T_{\mathrm{g}}{ }^{ \pm}$bands are close to the $T_{t}$ bands, and they appear slightly red-shifted or blue-shifted depending on the matrix site.

Additionally, the $C_{t}$ form is much more stable for PA-OD than for PA-OH, which allowed us to perform pumping experiments with the $C_{t}$ conformer of PA-OD. As seen in plot (c) of Fig. 5, excitation of the $2 \nu \mathrm{OD}$ of the $C_{t}$ molecules previously produced in the $\mathrm{LF}$ site leads to the $C_{t} \rightarrow T_{t}$ isomerization.

\subsection{Tunnelling rate for the $\mathrm{C}-\mathrm{O}$ isomerization}

For PA-OH, the $C_{t} \rightarrow T_{t}$ tunnelling is faster than the analogous cis $\rightarrow$ trans tunnelling for FA and AA (Fig. 4). ${ }^{28,29}$ The tunnelling rate for the $\mathrm{C}-\mathrm{O}$ isomerization observed for fully hydrogenated FA, AA and PA $\left(k_{t} \approx 2 \times 10^{-3}, 2 \times 10^{-2}\right.$, and $5 \times 10^{-2} \mathrm{~s}^{-1}$, respectively) correlates inversely with the barrier height for the isomerization, i.e., the higher barriers reasonably correspond to slower tunnelling rates. The cis $\rightarrow$ trans barrier heights calculated in this study at the MP2/6-311++G(2d,2p) level of theory for FA, AA and PA, are 2676, 2308 and 2290 $\mathrm{cm}^{-1}$, respectively. The tunnelling rate for FA is one order of magnitude slower than for AA, thus, reflecting the considerably higher barrier for the cis $\rightarrow$ trans conversion in FA as compared with AA (the computational difference between the barriers $\approx 370 \mathrm{~cm}^{-1}$ ). For AA and PA, the calculated barrier heights differ only by $\approx 20 \mathrm{~cm}^{-1}$ and the tunnelling rates are closer to each other. The known solvation effect can change to some extent the relative energetics and the barriers, as it was discussed elsewhere, ${ }^{29}$ however, this energy change should be similar for the species under study.

For FA, deuteration of the hydroxyl group decreases the cis $\rightarrow$ trans tunnelling rate by a factor of $\approx 3 \times 10^{3}$ (from $2 \times 10^{-3}$ to $7 \times 10^{-7} \mathrm{~s}^{-1}$ ). For AA and PA, deuteration of the hydroxyl group decreases the tunnelling rate by even larger factors of $3 \times 10^{4}$ and $6 \times 10^{4}$ (from $2 \times 10^{-2}$ to $7 \times 10^{-7} \mathrm{~s}^{-1}$ for AA and from $5 \times 10^{-2}$ to $8 \times 10^{-7} \mathrm{~s}^{-1}$ for PA). It is remarkable that the effect of hydroxyl deuteration is higher for lower isomerization barriers. This effect is in contradiction with the expected trend for the penetration probability calculated according to the semi-classical WKB approximation. ${ }^{34}$ It is probable that the tunnelling rate depends essentially on additional factors like the nature and distribution of the vibrational energy levels involved in the tunnelling process as pointed out in our previous studies on FA and AA. ${ }^{28,29}$ Our present results support the previously suggested model. It should be also mentioned that the extraction of very small decay rates is complicated and produces a relatively large experimental error.

\subsection{IR induced trans $\rightarrow$ cis $\mathrm{C}-\mathrm{O}$ isomerization in the fully hydrogenated species}

For the three molecules under study, the quantum yields obtained for the trans $\rightarrow$ cis $\mathrm{C}-\mathrm{O}$ isomerization induced by excitation of the $2 \nu \mathrm{OH}$ mode of the ground state conformer are shown in Table 2. The strong decrease in the quantum yield from FA $(10-20 \%)^{26}$ to AA $(\approx 2 \%)^{28}$ was previously connected with the low-barrier methyl rotor in the latter molecule. The low-frequency modes of the methyl rotor are coupled with the initially excited mode or/and with intermediate vibrational modes participating in the energy relaxation, enhancing nonreactive relaxation channels. ${ }^{35}$ Vibrations with large amplitudes such as $\tau \mathrm{C}-\mathrm{O}$ and $\tau \mathrm{C}-\mathrm{CH}_{3}$ are usually very anharmonic and strong coupling between the two internal rotors in AA can be expected.

PA has one additional internal rotational degree of freedom when compared with $\mathrm{AA}$, the $\mathrm{C}_{\alpha}-\mathrm{C}$ torsion $\left(\tau \mathrm{C}_{\alpha}-\mathrm{C}\right)$. This
Table 2 Quantum yields for $\mathrm{C}-\mathrm{O}$ isomerization induced by excitation of the $2 \nu \mathrm{OH} / 2 \nu \mathrm{OD}$ modes of the fully hydrogenated and hydroxyldeuterated $\mathrm{FA},{ }^{26} \mathrm{AA},{ }^{28}$ and $\mathrm{PA}$

\begin{tabular}{llll}
$\begin{array}{l}\mathrm{C}-\mathrm{O} \text { isomerization } \\
\text { quantum yields }^{a}\end{array}$ & $\mathrm{FA}^{b}$ & $\mathrm{AA}$ & $\mathrm{PA}$ \\
\hline $2 \nu \mathrm{OH}$ & $1.7 \times 10^{-1}(\mathrm{~s} 2)$ & $2.2 \times 10^{-2}$ & $1.4 \times 10^{-2}$ \\
trans $\rightarrow$ cis & $7 \times 10^{-2}(\mathrm{~s} 1)$ & & \\
$2 \nu \mathrm{OD}$ & & & \\
trans $\rightarrow$ cis & - & $3.6 \times 10^{-3}$ & $3.2 \times 10^{-3}(\mathrm{HF})$ \\
$2 \nu \mathrm{OD}$ & & $1.2 \times 10^{-2}$ & $5.0 \times 10^{-3}(\mathrm{LF})$ \\
cis $\rightarrow$ trans & - & $1.4 \times 10^{-1}$
\end{tabular}

${ }^{a}$ The quantum yields have been estimated by eqn. (1), the estimated error is $\pm 50 \%$. For PA, the trans and cis form correspond to $T_{t}$ and $C_{t}$, respectively. The two entries for FA and PA are associated with excitation of different sites ( $\mathrm{s} 1$ and $\mathrm{s} 2$ in FA, and HF and LF in PA). ${ }^{26,30 b}$ No kinetic data available for excitation of $2 \nu \mathrm{OD}$.

mode has a low vibrational frequency and it can contribute to the energy relaxation process in PA similarly to the $\tau \mathrm{C}-\mathrm{CH}_{3}$ mode. In fact, the computational frequency for the $\tau \mathrm{C}_{\alpha}-\mathrm{C}$ mode in $T_{t}$ is $57 \mathrm{~cm}^{-1}$, i.e. very close to the value of the Debye frequency for solid $\operatorname{Ar}\left(\approx 60 \mathrm{~cm}^{-1}\right),{ }^{36}$ which can favour energy transfer between lattice vibrations and molecular modes. Indeed, in addition to the $\mathrm{C}-\mathrm{O}$ internal rotation, excitation of the $2 \nu \mathrm{OH}$ mode of PA induces the $\mathrm{C}_{\alpha}-\mathrm{C}$ internal rotation indicating that the excitation energy is channelled efficiently into the low-frequency $\mathrm{C}_{\alpha}-\mathrm{C}$ torsional mode. The quantum yield for the $\mathrm{C}_{\alpha}-\mathrm{C}$ isomerization $\left(T_{t} \rightarrow T_{\mathrm{g}}{ }^{ \pm}\right)$is $1.4 \%$. Despite of this additional reaction channel, competing with the $\mathrm{C}-\mathrm{O}$ isomerization, the quantum yield for the $\mathrm{C}-\mathrm{O}$ isomerization in $\mathrm{PA}$ $(1.4 \%)$ is similar to the value for AA within our experimental error (see Table 2). A more quantitative analysis of the isomerization process should be based on the vibrational patterns in the overtone and combination spectral region derived from the precise anharmonic analysis. It is difficult to specify the involved relaxation channels for a relatively complicated system like PA with unknown anharmonic coupling between modes. In any case, the balance between the efficiency of the non-reactive and reactive channels is not changed significantly in PA as compared with AA. With respect to the $\mathrm{C}-\mathrm{O}$ isomerization, the participation of the $\mathrm{CH}_{3}$ group seems to be comparable to the effect of the $\mathrm{CH}_{3} \mathrm{CH}_{2}$ group. Thus, relatively large isomerization quantum yields may be expected for related molecules with longer carbon chains, which is an interesting direction of research.

\subsection{IR-induced trans $\rightarrow$ cis and $c i s \rightarrow$ trans $\mathrm{C}-\mathrm{O}$ isomerization in the OD-species}

The $T_{t} \rightarrow C_{t}$ isomerization quantum yield for PA-OD $(0.32-$ $0.50 \%)$ is similar to the value estimated for AA-OD $(0.4 \%)$. For both AA and PA, deuteration of the hydroxyl group decreases significantly the $\mathrm{C}-\mathrm{O}$ isomerization quantum yield. This phenomenon should not be correlated with the lower excitation energy upon pumping the $2 \nu \mathrm{OD}$ mode $(\approx 5100$ $\left.\mathrm{cm}^{-1}\right)$ when compared to the $2 \nu \mathrm{OH}$ mode $\left(\approx 6900 \mathrm{~cm}^{-1}\right)$ or with the change of the zero point vibrational energy. Indeed, it was shown for $\mathrm{FA}$ and $\mathrm{AA}$ that the $\mathrm{C}-\mathrm{O}$ isomerization quantum yields are nearly insensitive to the excitation energy as long as the energy is above the isomerization barrier. ${ }^{26,28}$ Our explanation for the deuteration effect observed in AA was based on the participation of higher order couplings between the $\tau \mathrm{C}-\mathrm{O}$ and the intermediate states involved in the IVR process for the OD species in comparison with the $\mathrm{OH}$ species. The higher order couplings for the OD species are due to a deuteration-induced decrease of the $\tau \mathrm{C}-\mathrm{O}$ frequency, and therefore, at similar energies the $\tau \mathrm{C}-\mathrm{O}$ mode is at a higher excited state in the OD species. This reduces the probability of 
energy transfer into the reaction coordinate for the deuterated species. ${ }^{28}$ In this study, we also observed a decrease of the $T_{t} \rightarrow$ $T_{\mathrm{g}}{ }^{ \pm}$quantum yield for PA-OD $(<0.2 \%)$ compared with PA$\mathrm{OH}(1.4 \%)$, indicating a significant effect even when the corresponding mode is not influenced much by deuteration. In order to justify this observation, we can speculate that the deuteration can decrease the coupling of the pumped mode $[2 \nu \mathrm{OH}(\mathrm{D})]$ with the reaction coordinate.

In the case of PA-OD, the estimated quantum yield is much larger for the reverse $C_{t} \rightarrow T_{t}$ conversion (14\%) than for the $T_{t} \rightarrow C_{t}$ conversion $(0.32-0.50 \%)$. This constitutes already the third reported observation pointing to the same direction, taking into account similar effects observed for the cis $\rightarrow$ trans isomerization in the AA-OD (Table 2) 2 $^{28}$ and HONO. ${ }^{1}$ For $\mathrm{HONO}$, the quantum yield higher by a factor of 7 was found for the IR-induced conversion of the cis conformer $(\mathrm{H}-\mathrm{O}-\mathrm{N}=\mathrm{O}$ dihedral angle of $\left.0^{\circ}\right)$ into the trans form $(\mathrm{H}-\mathrm{O}-\mathrm{N}=\mathrm{O}$ dihedral angle of $180^{\circ}$ ) when compared with the trans $\rightarrow$ cis process. ${ }^{1}$ Although the cis $\rightarrow$ trans energy barriers in AA and PA are lower than the trans $\rightarrow$ cis barriers, this fact is unable to fully justify the observed trend for two reasons: (1) the difference in the cis $\rightarrow$ trans and trans $\rightarrow$ cis barriers for HONO is very small $\left(130 \mathrm{~cm}^{-1}\right)$ and $(2)$ the quantum yields for FA and AA are quite independent of the excitation energy as long as the excited vibrational mode is above the isomerization barrier. ${ }^{1,26,28}$ In the case of HONO, it was suggested that kinetic or potential couplings between the excited vibrations and nearly resonant vibrational states could be responsible for the more efficient energy transfer from the excited states to the reaction coordinate upon excitation of the cis isomer. ${ }^{37,38}$ These factors may also be relevant for the carboxylic acids studied here.

\subsection{Site-selective isomerization of PA-OD}

Fig. 5 presents the result of irradiation for the hydroxyldeuterated $T_{t}$ conformer at two slightly different frequencies (5175 and $5170 \mathrm{~cm}^{-1}$ ). The pumping at different frequencies excites molecules in different local matrix morphologies (matrix sites). It is seen that the ratio of the $T_{t} \rightarrow C_{t}$ and $T_{t} \rightarrow T_{\mathrm{g}}{ }^{ \pm}$ reaction channels upon excitation of the $2 \nu \mathrm{OD}$ of $T_{t}$ depends on the matrix site, in particular, excitation of the HF site is more efficient in promoting the $\mathrm{C}_{\alpha}-\mathrm{C}$ internal rotation than excitation of the LF site. The quantum yields obtained for the $\mathrm{C}_{\alpha}-\mathrm{C}$ isomerization process differ by a factor of $\approx 4(0.16$ and $0.042 \%$ for HF and LF excitation, respectively) suggesting the site selectivity of this reaction channel (Table 3). On the other hand, the quantum yields for the $\mathrm{C}-\mathrm{O}$ isomerization upon pumping the HF and LF sites are similar within our experimental error $(0.32$ and $0.50 \%$ for $\mathrm{HF}$ and $\mathrm{LF}$ excitation, respectively). The latter result is similar to the data on FA where no reliable site dependence of the $\mathrm{C}-\mathrm{O}$ isomerization quantum yield has been observed. ${ }^{26}$ For PA, we can compare the isomerization quantum yields for the two isomerization processes for molecules isolated in the same matrix site. The $\mathrm{C}-\mathrm{O}$ isomerization is the preferred reaction channel for pumping of the LF site $\left(5170 \mathrm{~cm}^{-1}\right)$, and the $\mathrm{C}-\mathrm{O}$ isomerization quantum yield is higher than that associated with the $\mathrm{C}_{\alpha}-\mathrm{C}$ process by more than one order of magnitude. For pumping of the HF site $\left(5175 \mathrm{~cm}^{-1}\right)$, the two photoprocesses are nearly as efficient. The quantum yields given in Table 3 were estimated by the two different methods described earlier [eqns. (1) and (3)], and the obtained values are rather independent of the method used.

The site dependence of the quantum yields is possibly contributed by restrictions to the $\mathrm{C}_{\alpha}-\mathrm{C}$ internal rotation imposed by the matrix cage. Indeed, the $\mathrm{C}_{\alpha}-\mathrm{C}$ isomerization involves rotation of heavy atoms, and hence it is associated with a relatively large reaction volume compared with the $\mathrm{C}-\mathrm{O}$ isomerization, which deals essentially with motion of the light
Table 3 Quantum yields for $\mathrm{C}-\mathrm{O}$ and $\mathrm{C}_{\alpha}-\mathrm{C}$ isomerization induced by excitation of the $2 \nu \mathrm{OD}$ modes of PA-OD isolated in two matrix sites

\begin{tabular}{llc}
\hline Quantum yields $^{a} / 10^{-3}$ & HF site & LF site \\
\hline$T_{t} \rightarrow C_{t}(\mathrm{C}-\mathrm{O})$ & $3.2(3.5)$ & $5.0(5.5)$ \\
$T_{t} \rightarrow T_{\mathrm{g}}{ }^{ \pm}\left(\mathrm{C}_{\alpha}-\mathrm{C}\right)$ & $1.6(1.7)$ & $0.42(0.58)$
\end{tabular}

${ }^{a}$ The values obtained from eqn. (1) are shown outside the parentheses and the results obtained from eqn. (3) are shown in parentheses. An error of $\pm 50 \%$ is estimated.

hydroxylic hydrogen atom. These arguments were used previously to explain the lack of NIR induced isomerization in fumaric acid. ${ }^{39}$ However, in the case of PA, it was observed that the $T_{\mathrm{g}}{ }^{ \pm} \rightarrow T_{t}$ dark process is thermally activated, and it is in minute timescale at $15 \mathrm{~K}$. It follows that the corresponding barrier is quite low, which is consistent with the computational value of $\approx 60 \mathrm{~cm}^{-1}$. This suggests that the $T_{t} \rightarrow T_{\mathrm{g}}^{ \pm}$barrier should be relatively low as well (computationally $\approx 400 \mathrm{~cm}^{-1}$ ), which does not support cage restrictions. As another explanation, some specific energy relaxation channels can contribute to the site selectivity of the process. In this image, the coupling of $\tau\left(\mathrm{C}_{\alpha}-\mathrm{C}\right)$ with the lattice vibrations may be important. It should be also noted that the estimation of the $\mathrm{C}_{\alpha}-\mathrm{C}$ quantum yields can be influenced by the overlap of the $2 \nu \mathrm{OD}$ bands of the $T_{\mathrm{g}}{ }^{ \pm}$ and $T_{t}$ conformers. Inspection of the band profiles associated with the two sites leads to the conclusion that this overlap may occur only for the LF site, which, in principle, can contribute to the site selectivity of the $\mathrm{C}_{\alpha}-\mathrm{C}$ process, decreasing the $T_{\mathrm{g}}{ }^{ \pm}$ concentration for the LF pumping.

Another observation features unexpected energy redistribution in the molecule. The excitation of the $2 \nu \mathrm{OD}$ of $C_{t}$, which is mainly isolated in the $\mathrm{LF}$ site $\left(\mathrm{C}_{\alpha}-\mathrm{C}\right.$ resistant site), induced exclusively rotation around the $\mathrm{C}-\mathrm{O}$ axis leading to production of $T_{t}$, and no $\mathrm{C}_{\alpha}-\mathrm{C}$ isomerization $\left(C_{\mathrm{g}}{ }^{ \pm}\right)$could be detected. In fact, only the bands of $T_{t}$ increase under vibrational excitation of $C_{t}$ [spectrum (c) in Fig. 5]. This observation is remarkable since the computational $C_{t} \rightarrow T_{t}$ barrier is larger than the $C_{t} \rightarrow C_{\mathrm{g}}{ }^{ \pm}$barrier by $\approx 1700 \mathrm{~cm}^{-1}$ so that the opposite trend could be expected. This observation may be relevant to the site selectivity of the isomerization process because the opposite $T_{t} \rightarrow C_{t}$ process in this site also dominated over the $\mathrm{C}_{\alpha}-\mathrm{C}$ isomerization.

\section{Conclusions}

The quantum yields for the $\mathrm{C}-\mathrm{O}$ isomerization induced by excitation of the first overtone of the hydroxyl stretching vibration have been estimated for PA isolated in solid Ar, and compared with the corresponding data on FA and AA. ${ }^{26-28}$ The cis $\rightarrow$ trans tunnelling kinetics was also comparatively analysed. We observed the following trends:

(1) For the fully hydrogenated species, the $\mathrm{C}-\mathrm{O}$ isomerization quantum yields for PA and AA are one order of magnitude smaller than the value for FA, which is probably caused by a smaller vibrational density of states in the latter molecule. On the other hand, the quantum yields for PA and AA are remarkably similar despite the higher vibrational density of states in PA, thus, indicating a 'saturation' effect.

(2) Similarly to AA, deuteration of the hydroxyl group of PA decreases significantly the $\mathrm{C}-\mathrm{O}$ isomerization quantum yield. The explanation for the observed deuteration effect relies on the lower probability for energy transfer to the reaction coordinate in the deuterated species due to less efficient couplings between the initially excited vibrational mode and the $\tau \mathrm{C}-\mathrm{O}$ reactive mode.

(3) In the case of PA-OD, the $\mathrm{C}-\mathrm{O}$ and $\mathrm{C}_{\alpha}-\mathrm{C}$ isomerization quantum yields were estimated for excitation of molecules isolated in two matrix sites. A site-selective quantum yield 
was tentatively observed for the $\mathrm{C}_{\alpha}-\mathrm{C}$ isomerization whereas no significant site effect is found for the $\mathrm{C}-\mathrm{O}$ isomerization. The latter fact corresponds to the data obtained for AA and FA. ${ }^{26,28}$

(4) For AA-OD and PA-OD, the C-O isomerization starting from the higher energy arrangement of the carboxylic group (cis $\rightarrow$ trans in AA; and $C_{t} \rightarrow T_{t}$ in PA) was shown to be more efficient than the reverse process. This corresponds to the previous observations in $\mathrm{HONO},{ }^{1}$ and it is possibly explained by specific kinetic or potential couplings favouring the $c i s \rightarrow$ trans conversion. ${ }^{37,38}$

(5) For the fully hydrogenated species, the measured tunnelling rates correlate inversely with the computational isomerization barrier. Surprisingly, the deuteration effect (decrease of tunnelling rate by several orders of magnitude) is stronger for the lower isomerization barriers (AA and PA). This fact features the influence on the tunnelling mechanism of factors like distribution and nature of the vibrational energy levels involved in the process as proposed earlier for FA. ${ }^{29}$

The results obtained for PA support the conclusions derived previously for FA and AA and increase their confidence. However, understanding of a number of processes is still lacking, which suggests further studies in this field.

\section{Acknowledgements}

The Academy of Finland is thanked for financial support. E. M. and R. F. acknowledge the Portuguese Foundation for Science and Technology (PhD grant SFRH/BD/4863/2001 and POCTI/QUI/43366/2001).

\section{References}

1 L. Khriachtchev, J. Lundell, E. Isoniemi and M. Räsänen, J. Chem. Phys., 2000, 113, 4265.

2 A. J. Barnes, J. Mol. Struct., 1984, 113, 161.

3 M. Räsänen, H. Kunttu and J. Murto, Laser Chem., 1988, 9, 123

4 S. Sander, H. Willner, L. Khriachtchev, M. Pettersson, M. Räsänen and E. L. Varetti, J. Mol. Spectrosc., 2000, 203, 145.

5 M. Pettersson, J. Lundell, L. Khriachtchev and M. Räsänen, J. Am. Chem. Soc., 1997, 119, 11715.

6 E. M. S. Maçôas, L. Khriachtchev, M. Pettersson, J. Lundell, R. Fausto and M. Räsänen, Vib. Spectrosc., 2004, 34, 73.

7 H. H. Gunthard, J. Mol. Struct., 1984, 113, 141.

8 R. N. Perutz, Chem. Rev., 1985, 85, 77.

9 T. Lotta, J. Murto, M. Räsänen and A. Aspiala, J. Mol. Struct., 1984, 114, 333

10 S. Kudoh, M. Takayanagi, M. Nakata, T. Ishibashi and M. Tasumi, J. Mol. Struct., 1999, 479, 41

11 A. K. Knudsen and G. C. Pimentel, J. Phys. Chem., 1991, 95, 2823.

12 W. F. Hoffman and J. S. Shirk, Chem. Phys., 1983, 78, 331.

13 P. Roubin, S. Varin, P. Verlaque, S. Coussan, J. M. Berset, J. M. Ortega, A. Peremans and W. Q. Zheng, J. Chem. Phys., 1997, 107, 7800 .
14 M. Poliakoff and J. J. Turner, in Chemical and biochemical applications of lasers, ed. C. B. Moore, Academic, New York, 1980

15 H. Frei and G. C. Pimentel, Annu. Rev. Phys. Chem., 1985, 36, 491.

16 H. Frei and G. C. Pimentel, in Chemistry and Physics of MatrixIsolated Species, ed. L. Andrews and M. Moskovits, Elsevier, Amsterdam, 1989.

17 M. Räsänen and V. E. Bondybey, Chem. Phys. Lett., 1984, 111, 515.

18 M. Räsänen and V. E. Bondybey, J. Chem. Phys., 1985, 82, 4718.

19 M. Räsänen, J. Murto and V. E. Bondybey, J. Phys. Chem., 1985, 89, 3967.

20 V. E. Bondybey, Annu. Rev. Phys. Chem., 1984, 35, 591.

21 F. Legay, in Chemical and Biochemical Applications of Lasers, ed. C. B. Moore, Academic, New York, 1977.

22 E. M. S. Maçôas, L. Khriachtchev, M. Pettersson, R. Fausto and M. Räsänen, J. Am Chem. Soc., 2003, 125, 16188.

23 J. D. Goddard, Y. Yamaguchi and H. F. Schaefer, J. Chem. Phys., 1992, 96, 1158.

24 W. H. Hocking, Z. Naturforsch. A, 1976, 31, 1113.

25 M. L. Senent, Mol. Phys., 2001, 99, 1311.

26 E. M. S. Maçôas, L. Khriachtchev, M. Pettersson, J. Juselius, R. Fausto and M. Räsänen, J. Chem. Phys., 2003, 119, 11765.

27 M. Pettersson, E. M. S. Maçôas, L. Khriachtchev, R. Fausto and M. Räsänen, J. Am. Chem. Soc., 2003, 125, 4058.

28 E. M. S. Maçôas, L. Khriachtchev, M. Pettersson, R. Fausto and M. Räsänen, J. Chem. Phys., 2004, 121, 1331.

29 M. Pettersson, E. M. S. Maçôas, L. Khriachtchev, J. Lundell, R. Fausto and M. Räsänen, J. Chem. Phys., 2002, 117, 9095.

30 E. M. S. Maçôas, L. Khriachtchev, M. Pettersson, R. Fausto and M. Räsänen, unpublished.

31 M. J. T. Frisch, G. W. Schlegel, H. B. Scuseria, G. E. Robb, M. A Cheeseman, J. R. Zakrzewski, V. G. Montgomery, J. A. Stratmann, R. E. Burant, J. C. Dapprich, S. Millam, J. M. Daniels, A. D. Kudin, K. N. Strain, M. C. Farkas, O. Tomasi, J. Barone, V. Cossi, M. Cammi, M. Mennucci, B. Pomelli, C. Adamo, C. Clifford, S. Ochterski, J. Petersson, G. A. Ayala, P. Y. Cui, Q. Morokuma, K. Malick, D. K. Rabuck, A. D. Raghavachari, K. Foresman, J. B. Cioslowski, J. Ortiz, J. V. Baboul, A. G. Stefanov, B. B. Liu, G. Liashenko, A. Piskorz, P. Komaromi, I. Gomperts, R. Martin, R. L. Fox, D. J. Keith, T. Al-Laham, M. A. Peng, C. Y. Nanayakkara, A. Gonzalez, C. Challacombe, M. Gill, P. M. W. Johnson, B. G. Chen, W. Wong, M. W. Andres, J. L. Head-Gordon, M. Replogle and E. S. Pople, GAUSSIAN 98 (Revision A. 9), Gaussian, Inc., Pittsburgh, PA, 1998.

32 E. M. S. Maçôas, J. Lundell, M. Pettersson, L. Khriachtchev, R. Fausto and M. Räsänen, J. Mol. Spectrosc., 2003, 219, 70.

33 E. M. S. Maçôas, L. Khriachtchev, R. Fausto and M. Räsänen, J. Phys. Chem. A, 2004, 108, 3380.

34 R. P. Bell, The tunnel effect in chemistry, Chapman and Hall, New York, 1980.

35 A. Mcllroy and D. J. Nesbitt, J. Chem. Phys., 1994, 101, 3421.

36 H. J. Jodl, in Chemistry and Physics of Matrix-Isolated Species, ed. L. Andrews and M. Moskovits, Elsevier, Amsterdam, 1989.

37 Y. Guan, G. C. Lynch and D. L. Thompson, J. Chem. Phys., 1987, 87, 6957.

38 F. Richter, M. Hochlaf, P. Rosmus, F. Gatti and H. D. Meyer, J. Chem. Phys., 2004, 120, 1306.

39 E. M. S. Maçôas, R. Fausto, J. Lundell, M. Pettersson, L. Khriachtchev and M. Räsänen, J. Phys. Chem. A, 2001, 105, 3922. 